\title{
Review on Nitric Oxide, Carbon Monoxide and Antisense Based Therapy towards Treatment of Restenosis
}

\author{
Prathibha Ramadugu $^{1 *}$, Kanaka Latha Alikatte ${ }^{2}$, Narendar Dhudipala ${ }^{3}$ and Vikas Bommasane ${ }^{4}$ \\ ${ }^{1}$ Talla Padmavathi College of Pharmaceutical Sciences, Warangal, India \\ ${ }^{2}$ St. Peter's Institute of Pharmaceutical Sciences, Warangal, India \\ ${ }^{3}$ University College of Pharmaceutical Sciences, Warangal, India \\ ${ }^{4}$ Analytical Department, Apotex, India
}

\begin{abstract}
Balloon angioplasty has shown tremendous improvement in the treatment of atherosclerosis, but arterial renarrowing (restenosis) exists despite the benefits of intravascular devices called stents. Nitric Oxide (NO), carbon monoxide (CO) and Antisense therapy is some of the new potential treatment modalities. NO deficiency is associated with several vascular occlusive diseases, since NO regulates diverse aspects of blood vessel functions. More restricted human studies and several preclinical studies suggest that, NO supplement may solve the restenosis problem, although the data do not conclusively demonstrate this effect. $\mathrm{CO}$, similar to NO, inhibits vascular smooth muscle cells (VSCM) proliferation and in turn relaxes blood vessels and inhibits platelet aggregation. Thus it is recently suggested that inhaling $\mathrm{CO}$ could address the restenosis problem. Recent advances in vascular gene transfer have shown positive results for cardiovascular diseases, particularly in the treatment of restenosis. Uncoiling the DNA, transcription of DNA, export of RNA, DNA splicing, RNA stability or RNA transcription involved in the synthesis of proteins in cellular proliferation are some of the process involving antisense based approach. This review focuses on discussing the recent advancements in the treatment of restenosis.
\end{abstract}

Keywords: Restenosis; Nitric oxide; Carbon monoxide; Antisense; Angioplasty

\section{Introduction}

Report form American Heart Association that is published in 2014 highlights the unremitting predominance of cardiovascular disease (CVD) as a cause of morbidity and mortality [1,2]. One-third of the global mortality and the leading cause of death in the US and Europe is attributed to cardiovascular maladies. In US alone, more than half of all cardiovascular events in men and women under age of 75 reflect ischemic coronary heart diseases, which are elicited by coronary artery in which the lumen is narrowed by advanced atherosclerosis. A major breakthrough in cardiovascular therapy was established in 1977, when the first percutaneous transluminal coronary angioplasty (PTCA) by using an inflatable balloon catheter to dilate an obstructed coronary segment. A surgical or non-surgical procedure to remove the blockade may fail as a result of several unfavorable combinations, which can increase the likelihood of an adverse event or death. Indeed, $40 \%$ of the cases that received PCTA experienced recurrent myocardial ischemia, due to re narrowing of the treated artery within 6 months.

\section{Arterial injury response to neointimal hyperplasia}

Neointimal hyperplasia $(\mathrm{NH})$ is an exaggerated healing process that occurs in the vessel wall after injury. $\mathrm{NH}$ is responsible for restenosis, limiting the success of many cardiovascular procedures. The development of $\mathrm{NH}$ is a complex process initiated by injury and exposure to the vascular smooth muscle cells (VSMC) to circulating blood elements. The process is further explained in the following steps (Figure 1) (Table 1).

Despite having the success of treating coronary heart diseases by angioplasty, still there is tremendous need for addressing restenosis [3-8]. Several pharmaceutical approaches including delivery of antihypertensive agents, calcium channel blockers, lipid-lowering drugs and antioxidants have shown limited success in treating restenosis $[5,6,9,10]$. Best and most acceptable way to reduce restenosis rate in the clinic is with stents, by providing a larger initial lumen diameter, covering vessel dissections and supporting the expanded artery with sufficient rigidity $[11,12]$. Although there is some success with restenosis problem by utilizing stent based approach, there is still a need for anti restenotic drug-based therapy. In the quest for this process, several therapies were studied and discussed in the following sections.

\section{Nitric oxide based therapy in treating/preventing restenosis}

Several research groups have demonstrated the role of nitric oxide (NO) in the regulation of neointimal hyperplasia. Any defect in the pathway of NOS/NO pathway promote abnormal remodeling and neointimal hyperplasia. NO based therapy has shown several mechanisms in regulating the vascular smooth muscle cell (VSCM) proliferation neointimal hyperplasia. Some of the several effects of NO on neointimal hyperplasia include,

i) Inhibition of platelet aggregation and adhesion

ii) Inhibition of leukocyte chemotaxis

iii) Inhibition of vascular smooth muscle cell proliferation and migration

iv) Stimulation of VSMC apoptosis

*Corresponding author: Prathibha Ramadugu, Kakatiya Institute of Pharmaceutical Sciences, Pembarthi, Warangal, India, Tel: 040-27626194; Fax: 040-27666347; E-mail: ramaduguprathibha@gmail.com

Received December 28, 2015; Accepted January 03, 2016; Published January 10,2016

Citation: Ramadugu P, Alikatte KL, Dhudipala N, Bommasane V (2016) Review on Nitric Oxide, Carbon Monoxide and Antisense Based Therapy towards Treatment of Restenosis. J Bioequiv Availab 8: 059-063. doi:10.4172/jbb.1000268

Copyright: (c) 2016 Ramadugu P, et al. This is an open-access article distributed under the terms of the Creative Commons Attribution License, which permits unrestricted use, distribution, and reproduction in any medium, provided the original author and source are credited. 


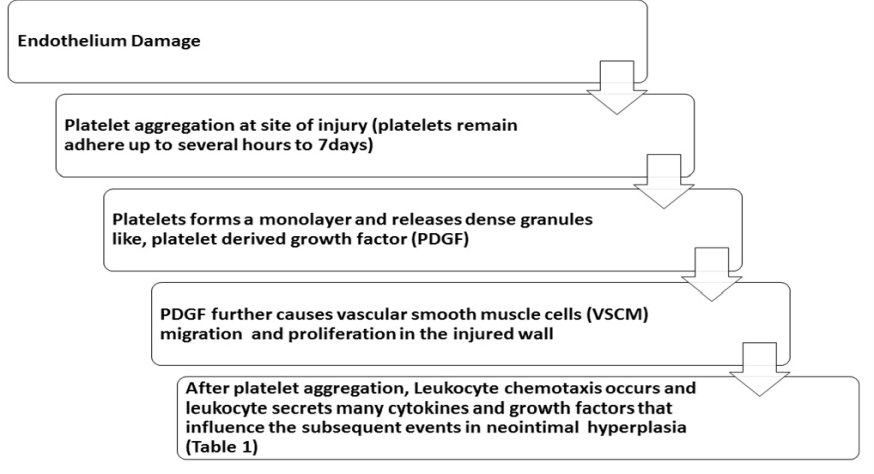

Figure 1: Step by step process depicting the pathogensis of neointimal hyperplasia.

\begin{tabular}{|c|c|c|c|}
\hline \multirow[b]{2}{*}{$\begin{array}{c}\text { Growth Factors, } \\
\text { Cytokines }\end{array}$} & \multicolumn{3}{|c|}{ Cell Source } \\
\hline & Leukocytes & $\begin{array}{l}\text { Monocytes, } \\
\text { macrophages }\end{array}$ & Mast Cells \\
\hline IGF-I & & $x$ & \\
\hline PDGF & & $X$ & $x$ \\
\hline TGF- $\alpha$ & & $x$ & \\
\hline TGF- $\beta$ & $x$ & $x$ & $x$ \\
\hline VEGF & $x$ & $x$ & $x$ \\
\hline EGF & & $x$ & \\
\hline FGF & & $X$ & \\
\hline TNF- $\alpha$ & $x$ & $x$ & $\mathrm{X}$ \\
\hline IL-I & $x$ & $x$ & $X$ \\
\hline IL-4 & $x$ & & $x$ \\
\hline IL-6 & & $x$ & $x$ \\
\hline IL-8 & $x$ & $x$ & $x$ \\
\hline IL-10 & & $x$ & $x$ \\
\hline IL-18 & $x$ & $x$ & $x$ \\
\hline MCP & $x$ & $x$ & $\mathrm{X}$ \\
\hline
\end{tabular}

Table 1: Cellular sources of growth factors and cytokines involved in the pathogenesis of fibroproliferative vasculopathies. Adapted from Mirtra el al. [2].

v) Stimulation of endothelial cell proliferation

vi) Inhibition of endothelial cell apoptosis

Given the role of NO in maintaining a normal vascular environment, many research groups have studied the effect of replacement of $\mathrm{NO}$ at the site of injury would prevent development of neointimal hyperplasia. Sadaf and co-workers have attempted to summarize the NO-based therapies that have been investigated and presented in the form of a table [13].

\section{Inhalation of nitric oxide}

Lee and co-workers have studied the effect of inhalation of nitric oxide (NO) on neointimal hyperplasia after balloon injury of the rat carotid artery. The results from the studies confirmed that, there was a $43 \%$ reduction in the Intima-Media ( $/ / \mathrm{M})$ area ratio in rats. Inhalation on NO for the period of 2 weeks have shown the reduction in $\mathrm{I} / \mathrm{M}$ area, whereas treating the injured artery for 1 week showed no difference in the I/M area ratio. But in contrast, studies by Rich et al. demonstrated that the levels of $\mathrm{NO}$ were undetectable in the artery of isolated perfused rat lungs ventilated with $\mathrm{NO}[14]$.

\section{Administration of nitric oxide donors systemically}

NO precursor, L-arginine was administered to the rabbits after balloon angioplasty to thoracic aorta by Mc Namara and co-workers [15]. L-arginine was administered from 2 days before to 2 weeks after angioplasty and the results showed that there was 39\% decrease in neointimal hyperplasia compared to control. To further confirm the effect of $\mathrm{NO}$ as therapeutic agent in decreasing the neointimal hyperplasia, NO inhibitor L-NAME was co-administered with $\mathrm{L}$-arginine reduced the effect in decreasing the neointimal hyperplasia. In another study by Chen et al administration of L-arginine $(2.5 \mathrm{mg} /$ $\mathrm{mL}$ ) in drinking water of rats reduced the $\mathrm{I} / \mathrm{M}$ area ratio by $65 \%$ and $26 \%$ reduction in the intimal cell proliferation compared to controls [16-18]. Despite the success in animal models, no human trials have demonstrated the clinical efficacy of systemic L-arginine administration.

Groves and co-workers have studied the effect of systemic administration of No donor molsidomine every $8 \mathrm{~h}$ for $48 \mathrm{~h}$ in porcine carotid balloon angioplasty and the results showed $32 \%$ reduction in neointimal hyperplasia at 21 days. However, the effect was observed only when the internal elastic lamina remained intact after angioplasty. Unfortunately, administration of systemic NO has not consistently demonstrated inhibition of neointimal hyperplasia in human subjects. In another study, Angioplastic, Coronaire, Corvasal, Diltiazem study showed that patients receiving NO from intravenous linsidomine, followed by oral molsidomine for a total of 6 months, had a significant improvement with a $10 \%$ reduction in lumen diameter [19]. In addition to the conflicting results in human clinical studies; vasodilatation, hypotension, headaches and increased bleeding complications limited its clinical applications.

\section{Nitric oxide synthase gene therapy}

Development in the field of gene transfer techniques has major impact in treating vascular disease; especially much effort has been invested in studying the effects of NOS gene transfer to treat neointimal hyperplasia. Sendai virus was first investigated by vonder Leyen to transfer eNOS to rat carotid arteries after balloon angioplasty [20]. The results from the studies demonstrated $\sim 70 \%$ reduction in neointimal hyperplasia were observed at the end of 2 weeks. Similarly, Chen and co-workers used retrovirus to transfect VSCM with eNOS and the results concluded $\sim 37 \%$ reduction in neointimal hyperplasia at 2 weeks after injury. Gene transfer of inducible NOS (iNOS) has demonstrated similar effects on neointimal hyperplasia. Adenoviral delivery of human iNOS to rat carotid artery resulted in 95\% reduction in intimal thickening at 2 weeks [21].

\section{Local delivery of nitric oxide donors}

Many investigators have studied the release of NO locally at the site of arterial injury. Biocompatibility is the primary issue to be focused during the selection of polymer containing NO-donating groups, because polymer induced inflammation has been reported by several research groups [15,22]. A combination of polymers could theoretically offer a more versatile release profile, but such complex coating would likely to cause biocompatibility issues. Several research groups have studied and reported use of NO-releasing polymers locally. Marks and co-workers investigated the effect of polythiolated bovine serum albumin modified to carry several S-nitrosothiol groups, on arterial balloon injury in rabbits [23]. Results from the studies showed that, development of neointimal hyperplasia reduced by $~ 77 \%$ when compared to control. Similar results were obtained when vein grafts 
treated with L-arginine increased NO levels and reduce neointimal hyperplasia in rabbit vein graft model.

\section{NO-releasing prosthetic materials}

Despite the advantages of several therapies mentioned to deliver NO in treating neointimal hyperplasia, there exist some clinical limitations because of systemic side effects, biocompatibility issues, complicated delivery schemes, or inability to delivery $\mathrm{NO}$ at the site for prolong period of time. To overcome these problems, recent research has focused on delivering NO through NO-releasing prosthetic materials. Yoon and co-workers utilized NO donor sodium nitroprusside to incorporate into a metallic stent coated with polyurethane polymer to investigate the effect on neointimal hyperplasia [24]. The stented arteries showed increased release of $\mathrm{NO}$ and also showed increased local cGMP levels, but failed to show the difference in the neointimal area compared to control. Later, two research groups Hou et al. and Do et al. demonstrated a reduction in neointimal area with $\mathrm{NO}$-eluting stent [25-27]. Hou and co-workers have demonstrated the use of silicone containing sodium nitroprusside to coat the interior of a selfexpanding polytetrafluoreethylene stent. From the studies it was found that, the mean neointimal area was reduced from $2.4 \mathrm{~mm}^{2}$ for control stents to $0.49 \mathrm{~mm}^{2}$ for NO-eluting stets, which corresponds to $24 \%$ reduction of angiographic vessel narrowing.

Recently, prosthetic bypass grafts are modified with NO-releasing molecules and utilized for delivering NO. Research in this field is focusing mainly on the biomechanics of NO release and the effect of these alterations on the prosthetic materials. Smith et al were the first to study the effect of diazeniumdiolated polymers incorporation in vein grafts $[28,29]$. The results showed that, NO release was achieved immediately, but the long-term biocompatibility limited its potential application. Later, Zhang and co-workers incorporated diazeniumdiolated silica nanoparticles into vascular grafts by embedding them into hydrophobic matrices in the rabbit model [30]. Unfortunately, the vascular grafts showed leaching and measurable levels of carcinogens (nitrosamines) were formed. Therefore, the investigators have attempted to coat grafts with layers of polyvinyl chloride or covalently binding diazeniumdiolates into a polyurethane backbone to prevent leaching of the NO-releasing prosthetic materials.

The main consideration in choosing NO based therapy is due to its antithrombotic, anti-proliferative, anti-inflammatory and vasorelaxant activity. Also, NO insufficiency is a crucial contributor to many occlusive vascular diseases. Human clinical trial data are limited, and conclusively demonstrates that NO based therapy can prevent restenosis in humans is currently lacking [31,32]. Nonetheless, when NO-donors administered systemically, they are prone to express eNOS which may inhibit angiographic restenosis in some clinical studies involving coronary heart disease patients [33]. Therefore, NO based therapies have potential inhibitory role in the development of neointimal hyperplasia.

\section{Carbon monoxide based therapy}

Some recent studies demonstrated that heme oxygenase-1endogenous carbon monoxide-cycle guanosine monophosphate cell signaling system involve in many pathogphsiological processes and the regulation of cardiovascular system. Heme oxygenase-1 (HO-1), the cytoprotective enzyme responsible for the generation of endogenous CO, was shown to regulate endothelial cell proliferation in vitro [34]. However, the role and the mechanism of action of HO-1 and $\mathrm{CO}$ in endothelial cell repair after trauma have not been evaluated. $\mathrm{CO}$, like the other similar diatomic gas NO, inhibits VSMCs proliferation by activating soluble guanylate cyclase and elevating intracellular sGMP levels. This in turn relaxes blood vessels and inhibits platelet aggregation. Recently it is suggested that endogenous CO play an important role in regulating vascular tone under both physiological and pathological conditions.

The fact that NO promotes the proliferation of endothelial cells and mobilization of endothelial progenitor cells prompted several research groups to investigate the hypothesis that endothelial eNOS may play a role in the effects of $\mathrm{CO}$ on endothelial cells [35-38]. Otterbein and co-workers have demonstrated that a 1-hour exposure to $\mathrm{CO}$ at low, nontoxic concentrations before injury, with no further treatment, prevented the development of intimal hyperplasia caused by balloon angioplasty via direct effects on VSMC proliferation [39]. In another study by Wegiel and co-workers, they demonstrated the effects of both $\mathrm{CO}$ and a CO-releasing molecule (CORM) on the augmentation of endothelial cell proliferation and migration to the injured site in rodent models. Authors conclude from the data that, one mechanism by which $\mathrm{CO}$ might promote cell growth is through phosphorylation of eNOS and activation of protein kinase $\mathrm{B}$ and retinoblastoma. The ability of $\mathrm{CO}$ to increase eNOS phosphorylation, however, may occur indirectly through an upstream potassium channel-mediated event. The results from their study concluded that, $\mathrm{CO}$ accelerates reendothelialization of the injured vessel and reported eNOS and NO as essential source for the CO effect. Despite the potential application of CO in treating restenosis, the safety and tolerability in human subjects still needs to be evaluated $[40,41]$.

\section{Antisense}

Antisense approach refers to the use of synthetic oligonucleotides or RNA transcripts, which are designed to interrupt synthesis of specific proteins. The antisense approach to inhibit gene expression involves, introducing oligonucleotides complementary to mRNA into cells in order to block any one of the following processes: uncoiling of DNA, mRNA transport from the nucleus to the cytoplasam, intracellular sequestration of the molecule, RNA stability, ribosome assembly, or RNA translation involved in the synthesis of proteins in cellular proliferation [42-48].

One of the potential clinical applications of antisense therapy is the prevention or treatment of restenosis following coronary interventions. The clinical applicability of antisense technology, remains limited due to relative lack of specificity, slow uptake across the cell membrane and rapid intracellular degradation of the oligonucleotides.

A number of animal models include, injured rat carotid model, porcine coronary angioplasty, have been used to demonstrate the effect of antisense oligonucleotides on restenosis. However, unlike human coronaries, rat carotid is completely dependent on SMC migration from the median [49]. Whereas, porcine coronary angioplasty model was comparatively expensive.

Several steps are generally required to document the biological effect of antisense oligonucleotides therapy includes:

i) Target gene mRNA or protein levels should be determined in both treated and control groups.

ii) Further, biological function of the gene should be assessed to demonstrate the activity.

iii) Finally, a specific biological effect should be demonstrated. 
Citation: Ramadugu P, Alikatte KL, Dhudipala N, Bommasane V (2016) Review on Nitric Oxide, Carbon Monoxide and Antisense Based Therapy towards Treatment of Restenosis. J Bioequiv Availab 8: 059-063. doi:10.4172/jbb.1000268

Despite the apparent success of antisense oligonucleotides therapy, there exist several limitations for this technology. The oligonucleotides must effectively cross the cell membrane to reach nucleus and must be resistant to degradation. Affinity and specificity towards the target gene is another potential aspect, which needs to be further studied [50]. Due to the strong negative charge present on the surface of the oligonucleotides, prevents them from passing the cell surface passively. However, uptake of oligonucleotides is determined by various factors include, length of the oligonucleotides, total charge of the molecule, lipid solubility and nucleotide concentration [51,52].

Earlier attempts to deliver oligonucleotides to treat/prevent restenosis are by surgical application. The initial clinically applicable devices were catheter-based, which allows the local delivery of oligonucleotides. Phosphorothioate oligonucleotides first utilized the combination strategy of antisense targeting to c-Myc with catheter based delivery to pigs for prevention of restenosis [53]. However, the bolus injection produced a reduction in heart rate, blood pressure and cardiac output in primate models $[54,55]$. Further development in the field of oligonucleotides delivery includes polymer-coated stents to deliver micromolar concentrations of c-Myc antisense phosphorodiamidate morpholino oligomers (PMO) into vessel walls. Gelatin-coated platinum-iridium stents used to deliver c-Myc antisense oligonucleotides in rabbits have been successfully demonstrated by Zhang and co-workers [56].

The first clinical study demonstrated the safety and feasibility of local delivery of antisense in the treatment and prevention of restenosis. Several studies demonstrated the endoluminal delivery of advanced c-Myc antisense PMO into coronary arteries of rabbit following stent implantation. Kipshidze and co-workers have demonstrated the complete inhibition of c-Myc expression and a significant reduction of the neointimal formation in dose dependent fashion while allowing for complete vascular healing. In another study by same research group, similar results were obtained after implantation of advanced c-Myc antisense PMO eluting phosphorylcholine coated stents in porcine coronary model (Figure 1). Advantage of antisense PMO over other more destructive methods, such as brachytherapy or cytotoxic inhibitors can be accountable to the success of $40 \%$ reduction in intima in the absence of endothelial toxicity $[57,58]$.

\section{Conclusion}

With increasing trends in the people affected by coronary heart diseases and the advances in technology the treatments for CRD using intervention techniques will increase. The physicians for patients with multivessel disease, diabetes, etc. may also follow intervention treatments. Despite the advantages from intervention therapies there are also limitations like restenosis, which can be solved by using different non-interventional therapies. More research advances addressing the limitations associated with the existing therapies will further benefit the population that is affected by CRD.

\section{References}

1. Go AS, Mozaffarian D, Roger VL, Benjamin EJ, Berry JD, et al. (2014) Heart disease and stroke statistics--2014 update: a report from the American Heart Association. Circulation 129: e28-e292.

2. Mitra AK, Del Core MG, Agrawal DK (2005) Cells, cytokines and cellular immunity in the pathogenesis of fibroproliferative vasculopathies. Can J Physiol Pharmacol 83: 701-715.

3. Arjomand H, Turi ZG, McCormick D, Goldberg S (2003) Percutaneous coronary intervention: historical perspectives, current status, and future directions. Am Heart J 146: 787-796.
4. Rajagopal V, Rockson SG (2003) Coronary restenosis: a review of mechanisms and management. Am J Med 115: 547-553.

5. Beyar R (2004) Novel approaches to reduce restenosis. Ann N Y Acad Sci 1015: 367-378.

6. Schiele TM, Krötz F, Klauss V (2004) Vascular restenosis-striving for therapy Expert Opin Pharmacother 5: 2221-2232.

7. Juluri A, Peddikotla P, Repka MA, Murthy SN (2013) Transdermal iontophoretic delivery of propofol: a general anaesthetic in the form of its phosphate salt. $J$ Pharm Sci 102: 500-507.

8. Xu X, Al-Ghabeish M, Rahman Z, Krishnaiah YS, Yerlikaya F, et al. (2015) Formulation and process factors influencing product quality and in vitro performance of ophthalmic ointments. Int J Pharm 493: 412-425.

9. Juluri A, Narasimha Murthy S (2014) Transdermal iontophoretic delivery of a liquid lipophilic drug by complexation with an anionic cyclodextrin. J Control Release 189: 11-18.

10. Juluri A, Modepalli N, Jo S, Repka MA, Shivakumar HN, et al. (2013) Minimally invasive transdermal delivery of iron-dextran. J Pharm Sci 102: 987-993.

11. Lau KW, Mak KH, Hung JS, Sigwart U (2004) Clinical impact of stent construction and design in percutaneous coronary intervention. Am Heart $\mathrm{J}$ 147: 764-773.

12. Schwartz RS, Chronos NA, Virmani R (2004) Preclinical restenosis models and drug-eluting stents: still important, still much to learn. J Am Coll Cardiol 44: 1373-1385.

13. Ahanchi SS, Tsihlis ND, Kibbe MR (2007) The role of nitric oxide in the pathophysiology of intimal hyperplasia. J Vasc Surg 45 Suppl A: A64-73.

14. Rich GF, Roos CM, Anderson SM, Urich DC, Daugherty MO, et al. (1993) Inhaled nitric oxide: dose response and the effects of blood in the isolated rat lung. J Appl Physiol 75: 1278-1284.

15. McNamara D, Bedi B, Aurora H, Tena L, Ignarro LJ, et al. (1993) L-arginine inhibits balloon catheter-induced intimal hyperplasia. Biochem Biophys Res Commun 193: 291-296.

16. Chen C, Mattar SG, Lumsden AB (1999) Oral administration of L-arginine reduces intimal hyperplasia in balloon-injured rat carotid arteries. J Surg Res 82: $17-23$.

17. Loria MJ, White SW, Robbins SA, Salmeto AL, Hymel KA, et al. (2013) Brainderived neurotrophic factor response in vulnerable and resilient genetic lines in the chick anxiety-depression model. Behav Brain Res 245: 29-33.

18. Manda P, Sammeta SM, Repka MA, Murthy SN (2012) lontophoresis across the proximal nail fold to target drugs to the nail matrix. J Pharm Sci 101: 2392 2397.

19. Lablanche JM, Grollier G, Lusson JR, Bassand JP, Drobinski G, et al. (1997) Effect of the Direct Nitric Oxide Donors Linsidomine and Molsidomine on Angiographic Restenosis after Coronary Balloon Angioplasty. The ACCORD Study. Angioplastic Coronaire Corvasal Diltiazem. Circulation 95: 83-89.

20. von der Leyen HE, Gibbons GH, Morishita R, Lewis NP, Zhang L, et al. (1995) Gene therapy inhibiting neointimal vascular lesion: in vivo transfer of endothelial cell nitric oxide synthase gene. Proc Natl Acad Sci U S A 92: 1137-1141.

21. Shears LL 2nd, Kibbe MR, Murdock AD, Billiar TR, Lizonova A, et al. (1998) Efficient inhibition of intimal hyperplasia by adenovirus-mediated inducible nitric oxide synthase gene transfer to rats and pigs in vivo. J Am Coll Surg 187: 295-306.

22. Lee JS, Adrie C, Jacob HJ, Roberts JD Jr, Zapol WM, et al. (1996) Chronic inhalation of nitric oxide inhibits neointimal formation after balloon-induced arterial injury. Circulation Res 78: 337-342.

23. Marks DS, Vita JA, Folts JD, Keaney Jr JF, Welch GN, et al. (1995) Inhibition of neointimal proliferation in rabbits after vascular injury by a single treatment with a protein adduct of nitric oxide. J Clin Invest 96: 2630-2638.

24. Yoon JH, Wu CJ, Homme J, Tuch RJ, Wolff RG, et al. (2002) Local delivery of nitric oxide from an eluting stent to inhibit neointimal thickening in a porcine coronary injury model. Yonsei Med J 43: 242-251.

25. Do YS, Kao EY, Ganaha F, Minamiguchi H, Sugimoto K, et al. (2004) In-stent restenosis limitation with stent-based controlled-release nitric oxide: initial results in rabbits. Radiology 230: 377-382. 
Citation: Ramadugu P, Alikatte KL, Dhudipala N, Bommasane V (2016) Review on Nitric Oxide, Carbon Monoxide and Antisense Based Therapy towards Treatment of Restenosis. J Bioequiv Availab 8: 059-063. doi:10.4172/jbb.1000268

26. Hou D, Narciso H, Kamdar K, Zhang P, Barclay B, et al. (2005) Stent-based nitric oxide delivery reducing neointimal proliferation in a porcine carotid overstretch injury model. Cardiovasc Intervent Radiol 28: 60-65.

27. Yang Y, Manda P, Pavurala N, Khan MA, Krishnaiah YS (2015) Development and validation of in vitro-in vivo correlation (IVIVC) for estradiol transdermal drug delivery systems. J Control Release 210: 58-66.

28. Smith DJ, Chakravarthy D, Pulfer S, Simmons ML, Hrabie JA, et al. (1996) Nitric oxide-releasing polymers containing the [N(O)NO]- group. J Med Chem 39: $1148-1156$

29. Manda P, Angamuthu M, Hiremath SR, Raman V, Murthy SN (2014) lontophoretic drug delivery for the treatment of scars. J Pharm Sci 103: 1638 1642.

30. Zhang H, Annich GM, Miskulin J, Osterholzer K, Merz SI, et al. (2002) Nitric oxide releasing silicone rubbers with improved blood compatibility: preparation characterization, and in vivo evaluation. Biomaterials 23: 1485-1494.

31. Ziche M, Morbidelli L, Choudhuri R, Zhang HT, Donnini S, et al. (1997) Nitric oxide synthase lies downstream from vascular endothelial growth factorinduced but not basic fibroblast growth factor-induced angiogenesis. J Clin Invest 99: 2625-2634.

32. Murohara T, Asahara T, Silver M, Bauters C, Masuda H, et al. (1998) Nitric oxide synthase modulates angiogenesis in response to tissue ischemia. $\mathrm{J}$ Clin Invest 101: 2567-2578.

33. Kubes $P$, Suzuki M, Granger DN (1991) Nitric oxide: an endogenous modulator of leukocyte adhesion. Proc Natl Acad Sci U S A 88: 4651-4655.

34. Volti GL, Sacerdoti D, Sangras B, Vanella A, Mezentsev A, et al. (2005) Carbon monoxide signaling in promoting angiogenesis in human microvessel endothelial cells. Antioxid Redox Signal 7: 704-710.

35. López-Farré A, Sánchez de Miguel L, Caramelo C, Gómez-Macías J, Garcia R, et al. (1997) Role of nitric oxide in autocrine control of growth and apoptosis of endothelial cells. Am J Physiol 272: H760-768.

36. Ono Y, Ono H, Matsuoka H, Fujimori T, Frohlich ED (1999) Apoptosis, coronary arterial remodeling, and myocardial infarction after nitric oxide inhibition in SHR. Hypertension 34: 609-616.

37. Cooke JP (2005) ADMA: its role in vascular disease. Vascular Medicine 10: S11-S17.

38. Köllmer M, Popescu C, Manda P, Zhou L, Gemeinhart RA (2013) Stability of benzocaine formulated in commercial oral disintegrating tablet platforms. AAPS PharmSciTech 14: 1333-1340.

39. Otterbein LE, Zuckerbraun BS, Haga M, Liu F, Song R, et al. (2003) Carbon monoxide suppresses arteriosclerotic lesions associated with chronic graft rejection and with balloon injury. Nat Med 9: 183-190.

40. Chin BY, Jiang G, Wegiel B, Wang HJ, Macdonald T, et al. (2007) Hypoxiainducible factor 1 alpha stabilization by carbon monoxide results in cytoprotective preconditioning. Proc Natl Acad Sci U S A 104: 5109-5114.

41. Wegiel B, Gallo DJ, Raman KG, Karlsson JM, Ozanich B, et al. (2010) Nitric oxide-dependent bone marrow progenitor mobilization by carbon monoxide enhances endothelial repair after vascular injury. Circulation 121: 537-548.

42. Zamecnik PC, Stephenson ML (1978) Inhibition of Rous sarcoma virus replication and cell transformation by a specific oligodeoxynucleotide. Proc Natl Acad Sci 75: 280-284.

43. Morishita R, Kaneda Y, Ogihara T (2003) Therapeutic potential of oligonucleotide-based therapy in cardiovascular disease. BioDrugs 17: 383389.

44. Wang AM, Creasey AA, Ladner MB, Lin LS, Strickler J, et al. (1985) Molecular cloning of the complementary DNA for human tumor necrosis factor. Science 228: 149-154.
45. Popescu C, Manda P, Juluri A, Janga KY, Cidda M, et al. (2015) Enhanced Dissolution Efficiency of Zaleplon Solid Dispersions via Modified ß-Cyclodextrin Molecular Inclusion Complexes. J Pharm Pharm Scien 1: 12-21.

46. Juluri A, Popescu C, Zhou L, Murthy RN, Gowda VK, et al. (2015) Taste Masking of Griseofulvin and Caffeine Anhydrous Using Kleptose Linecaps DE17 by Hot Melt Extrusion. AAPS PharmSciTech .

47. Juluri A, Vanaja K, Murthy SN (2014) Passive delivery techniques for transcutaneous immunization. Journal of Drug Delivery Science and Technology 24: 271-276.

48. Manda P, Hargett JK, Vaka SR, Repka MA, Murthy SN (2011) Delivery of cefotaxime to the brain via intranasal administration. Drug Dev Ind Pharm 37: 1306-1310.

49. Wagner RW, Nishikura K (1988) Cell cycle expression of RNA duplex unwindase activity in mammalian cells. Mol Cell Biol 8: 770-777.

50. Stein CA, Cheng YC (1993) Antisense oligonucleotides as therapeutic agents-is the bullet really magical? Science 261: 1004-1012.

51. Villa AE, Guzman LA, Poptic EJ, Labhasetwar V, D'Souza S, et al. (1995) Effects of antisense c-myb oligonucleotides on vascular smooth muscle cell proliferation and response to vessel wall injury. Circ Res 76: 505-513.

52. Muller DW (1997) The role of proto-oncogenes in coronary restenosis. Prog Cardiovasc Dis 40: 117-128.

53. Shi Y, Fard A, Galeo A, Hutchinson HG, Vermani P, et al. (1994) Transcathete delivery of c-myc antisense oligomers reduces neointimal formation in a porcine model of coronary artery balloon injury. Circulation 90: 944-951.

54. Cornish K (1993) Cardiovascular effects of a phosphorothioate oligonucleotide with sequence antisense to p53 in the conscious rhesus-monkey. FASEB JOURNAL. Federation amer soc exp biol 9650 rockville pike, Bethesda, MD 20814-3998 USA.

55. Galbraith WM, Hobson WC, Giclas PC, Schechter PJ, Agrawal S (1994) Complement activation and hemodynamic changes following intravenous administration of phosphorothioate oligonucleotides in the monkey. Antisense Res Dev 4: 201-206.

56. Zhang XX, Cui CC, Xu XG, Hu XS, Fang WH, et al. (2004) In vivo distribution of c-myc antisense oligodeoxynucleotides local delivered by gelatin-coated platinum-iridium stents in rabbits and its effect on apoptosis. Chin Med J 117 258-263.

57. Herdeg C, Oberhoff M, Baumbach A, Blattner A, Axel DI, et al. (2000) Loca paclitaxel delivery for the prevention of restenosis: biological effects and efficacy in vivo. J Am Coll Cardiol 35: 1969-1976.

58. Sheppard R, Eisenberg MJ (2001) Intracoronary radiotherapy for restenosis. N Engl J Med 344: 295-297. 